\title{
El Circo de Buenos Aires y sus Prácticas: definiciones en disputa $^{1}$
}

\author{
Julieta Infantino ${ }^{2}$ \\ Universidad de Buenos Aires, Argentina \\ E-mail: julietainfantino@yahoo.com.ar
}




\section{Resumo}

O objetivo deste trabalho é analisar a disputa sobre a definição do gênero circo no processo de revitalização dessa arte na cidade de Buenos Aires, Argentina, durante o período compreendido entre a pós-ditadura e o contexto contemporâneo (1983-2013). As discussões sobre a forma de pensar essas artes se traduzem em dicotomias como popular/ refinado, contemporâneo/tradicional, transgressor/legitimado. As mesmas são apressentadas a partir de noções artísticas, estéticas, políticas e ideológicas diferenciais. No nosso caso, o gênero artístico, e seu potencial de inovação, constitui uma areia de disputa para a construção de identidades. O debate é caraterizado pelo potencial de gerar variantes ou estilos específicos a partir dos recursos de comunicação utilizados, bem como expandir o alcance das menssagens. Problematizaremos dissidências artístico-estilísticas estudando as manipulações de formas genéricas tradicionais e os debates ante a legitimação dessas artes que, historicamente, têm sido desvalorizadas de cânones hegemônicos de valor artístico.

Palavras-chave: Circo. Formação Cultural. Tradicionalização. Popularização.

\section{Abstract}

The purpose of this article is to analyze the way in which the definition of the circus genre was disputed in its process of re-emergence in the city of Buenos Aires, Argentine, among the period started in the post-dictatorship until the contemporary context (1983-2013). How to think these arts is a disputed field which results in dichotomies as popular / refined, contemporary / traditional, transgressive / legitimate stating different artistic, aesthetic, political and ideological positions. In our case study, the artistic gender and its possibilities for innovation establishes itself as an arena of dispute for the construction of identity. It is debated how far variants or particular styles from the communicative resources used can be generated and how far the range of messages can be extended. Dissent in the artistic-stylistic field will be analyzed through the manipulation of the traditional generic forms as well as discussions in the context of legitimation of arts that have historically been devaluated from evaluative hegemonic canons.

Keywords: Circus. Cultural Formation. Traditionalization, Popularization. 


\section{Introducción}

partir de los años post-dictatoriales (1983) hasta la actualidad,
diversas expresiones artísticas populares cobraron relevancia en la escena cultural de Buenos Aires, Argentina. Bailarines de murga o tango, artistas teatrales callejeros, músicos rioplatenses, entre otros, han recuperado y resignificado estas artes populares, demandando canales de reconocimiento e ingresando, en algunos casos y no sin conflictos, a circuitos legitimados de cultura en la ciudad. Las artes circenses tuvieron una particular historia en este proceso, situación que fue modificando paulatinamente su histórica desvalorización (SEIBEL, 1993; INFANTINO, 2012).

¿Cómo se dio el proceso por el cual una expresión artística como el circo, históricamente denotada como "arte menor" o "popular", comenzó a ocupar espacios legitimados de cultura, otrora exclusivos para la llamada "alta cultura"?¿Qué disputas se desencadenaron al interior del campo artístico en torno a la definición de estilos (artísticos, laborales, ideológicos) válidos y legítimos? Estas son algunas de las preguntas que guiaron nuestra investigación doctoral, cuyo objetivo general fue estudiar el proceso de reactivación y resignificación de saberes y prácticas populares impulsado en la Ciudad de Buenos Aires a través del caso de las artes circenses. Cabe destacar que hemos trabajado especialmente con un recorte que focaliza en nuevos actores sociales que no provienen de la tradición familiar circense y que comenzaron a recuperar estos lenguajes artísticos a partir del final de la última dictadura militar (1976-1983). El vínculo entre estos artistas y el llamado Circo Tradicional será estudiado desde el recorte antedicho³. 
Retomando algunos de los interrogantes expuestos, en este trabajo proponemos analizar el modo en que se debate, al interior de la formación cultural ${ }^{4}$ circense en la ciudad de Buenos Aires, la definición identitaria en tiempos de cambios, marcados por el ingreso de las artes circenses a espacios de legitimación artística.

Este proceso de legitimación de un arte históricamente denostado pondrá en evidencia las disputas en cuanto a cómo pensar estéticamente estas artes que se traducen en dicotomías como popular/refinado, contemporáneo/tradicional, trasgresor/legitimado. En el caso que presentaremos, el género artístico se instaura como arena de disputa en la dinámica de la construcción identitaria. Por lo tanto, problematizaremos los disensos en el terreno artístico-estilístico, estudiando las manipulaciones de las formas genéricas tradicionales, así como las disputas internas acerca de los límites de estas manipulaciones.

Asimismo, las maneras en que los artistas se han posicionado frente a agentes externos a la formación cultural -mercado, industrias culturales, agencias estatales- marcarán, en el terreno de las representaciones, algunas distinciones entre "auténticos" y "vendidos". Aquí, las nociones de autonomía, independencia, crítica, trasgresión que se consolidaron como marcas identitarias de la formación cultural, desde los años 90, se presentarán como eje de conflictos en las posturas de los artistas frente al contexto de legitimación de artes, que hasta el momento habían sido sistemáticamente descalificadas como artes menores y deslegitimadas.

\section{Géneros Artísticos y Adscripciones Identitarias}

El concepto de "identidad" conlleva una compleja carga de sentidos y se ha utilizado de diversas maneras a lo largo de la historia de la antropología. Aún siendo conscientes de la complejidad del término, consideramos que continúa siendo un concepto central cuando habilita los análisis sociales en términos de disputa y poder. En nuestro trabajo, uno de los puntos de partida para operacionalizar este concepto fue retomar una perspectiva relacional. Este abordaje remite a las elaboraciones de Frederic Barth, quien para mediados de los '70 en el marco de los estudios sobre etnicidad, propuso superar 
las perspectivas esencialistas que habían caracterizado al concepto. "La identidad" como conjunto de atributos culturales estáticos, que homogéneamente demarcan los límites de un grupo, fue suplantada por un concepto que sitúa a los procesos identitarios en el marco de la interacción social entre grupos, donde se producen los procesos de autoadscripción y adscripción por los otros (BARTH, 1976). Las propuestas contemporáneas que han discutido el concepto esencialista de identidad, permitieron apartarse de una visión homogénea y estática de la misma abordándola como un proceso. El mismo opera a través de la diferencia por medio de un trabajo discursivo, que genera la marcación de límites simbólicos, la producción de "efectos de frontera". Desde esta concepción, las identidades son estratégicas y posicionales, no están unificadas ni son singulares, sino más bien, múltiplemente construidas a través de diferentes discursos, prácticas y posiciones a menudo intersectadas y antagónicas (HALL, 1996; BRUBAKER-COOPER, 2001).

Esta perspectiva coloca en primer plano a la capacidad de agencia de los actores sociales. Los sujetos o grupos utilizan, representan y actúan estrategias de diferenciación. De este modo, se seleccionan y movilizan subconjuntos de "atributos culturales" con el objetivo de articular las fronteras de la diferencia (APPADURAI, 1996; GARCÍA CANCLINI, 2004). Los grupos generan adscripciones identitarias asumiendo discursos, estéticas y prácticas como lo propio a lo que adscriben, en relación/ tensión con lo otro (REGUILLO, 2000).

Otro atributo central en la construcción identitaria refiere a la capacidad de todo grupo humano para configurar y reconfigurar el pasado como una memoria colectiva compartida por sus miembros (paralela a la memoria biográfica constitutiva de las identidades individuales) (GIMÉNEZ, 1997). Esta propuesta teórica se puede operacionalizar a partir de los aportes y revisiones sobre los conceptos de género artístico y performance. En nuestro caso, los artistas circenses retomaron y resignificaron un género artístico al que dotaron de significaciones novedosas, poniendo en marcha procesos de tradicionalización, en tanto selección de un pasado significante para legitimar la práctica presente (BRIGGS-BAUMAN, 1992). En cada performance o puesta en 
acto se actualizan actuaciones anteriores, pero también se las recrea y adapta a nuevos contextos. La noción de cualidad emergente existente en toda performance, en la que se da una tensión dinámica entre lo socialmente dado, lo convencionalizado, el pasado y lo emergente, permite problematizar cómo los sujetos recurren a ciertos elementos del pasado para dar sentido a la actividad presente, para legitimar sus prácticas y disputar su reconocimiento.

En este sentido, se propone utilizar al concepto de género como un conjunto convencionalizado pero abierto a un espectro sensible e ilimitado de posibilidades. El género se constituye como un conjunto de recursos comunicativo-expresivos nucleares o prototípicos, que los distintos actores usan de manera diversa y que jamás permanecen fijos, sino que se negocian y cambian según los contextos de uso. Al enfrentarse a "géneros complejos", géneros que absorben y asimilan otros tipos genéricos, se cuestiona la noción de que los géneros configuran unidades no superpuestas, estáticas y estilísticamente homogéneas (BAJTÍN, 1992 [1979]).

Richard Bauman y Charles Briggs (1992) plantean la noción de "brecha intertextual" para referirse a la distancia que cada performance establece con versiones anteriores. Acercándose o alejándose de la performance de referencia, los sujetos recrean estructura, función, forma y significado del discurso, la expresión o el género artístico. Una performance puede estar conectada con sus precedentes genéricos de múltiples maneras y es por eso que las conformaciones genéricas suelen presentar mezclas y resultan muchas veces ambiguas y contradictorias Esta brecha intertextual puede ser minimizada o maximizada. Minimizar la distancia entre la performance y sus precedentes genéricos, se inscribe en una estrategia de conservación de la tradición genérica; en cambio,

(...) el hecho de maximizar y poner en relieve tales fisuras intertextuales contribuye a destacar las estrategias de construcción de autoridad por medio de exigencias de creatividad e innovación (...), por medio también a la resistencia a estructuras hegemónicas asociadas con géneros establecidos y de otros motivos de distanciamiento con respecto a sus precedentes textuales (BAUMANBRIGGS, 1996, p. 92). 
La propuesta teórico-metodológica expuesta hasta aquí permite dirigir la mirada al modo en que los sujetos o grupos, al seleccionar algunas prácticas o saberes culturales (y dejar otros de lado) y al manipular los géneros artísticos, legitiman la práctica actual, así como la propia identidad, estableciendo las "fronteras de la diferencia" entre el nosotros/otros (APPADURAI, 1996 [2001]). En nuestro caso, el género artístico se instaura como elemento en base al cual se construye la adscripción identitaria. La conformación del "nosotros" se debate, en relación con las posibilidades de generar variantes o estilos particulares a partir de los recursos comunicativos utilizados, los mensajes transmitidos y las formas de acercarse o alejarse de la tradición del género artístico. En lo que continúa, analizaremos cómo durante el proceso de resurgimiento de estas artes en la ciudad de Buenos Aires, las prácticas contemporáneas fueron manteniendo diversos vínculos con la "tradición" circense, instaurando variantes genéricas que entrarán en disputa en el contexto actual.

\section{La Manipulación y Tradicionalización del Género Artístico Circense}

La palabra tradición merece mucha reflexión. Esta cuestión de clasificar las cosas es muy compleja y la palabra tradición es más compleja. Un viejo cirquero, Pacheco, decía: el circo es el espectáculo más antiguo y más moderno de todos los tiempos. (...) Siempre se prueban cosas que no entran en el varieté, ni en el teatro. No, esto es para el circo. Está eso de clasificar todo. ¿Qué es, Nuevo Circo, Circo Tradicional, Anticirco? (Payaso Tomate, entrevista Julio, 2001).

El circo es un arte con una larga historia en Argentina. Tuvo sus "épocas de gloria" a fines del siglo XIX cuando fue reconocido como "cuna del teatro nacional", encarnado en el Circo Criollo de los hermanos Podestá (circo de primera parte de destrezas y segunda de arte teatral). Luego esta legitimidad transitoria fue desestimada, e históricamente ocupó espacios desvalorizados de arte en el país. Cabe destacar que las valoraciones jerárquicas del arte en la Argentina respondieron 
históricamente a la preponderancia de un canon estético clásico. Y el circo, desde sus orígenes como género artístico, se colocó en las antípodas de ese ideal clasicista: apelando a una estética grotesca con cuerpos de dimensiones exageradas sobre zancos, enanos, freaks (en referencia a personas que por alguna característica peculiar o fuera de lo común, frecuentemente "deformaciones corporales", eran exhibidos como "curiosidades" en los circos), mujeres barbudas, narices prominentes, sonrisas exageradas. El circo, entonces, se asentó destacando aquello que el hombre moderno debía controlar: las pasiones, el goce, la risa, la imaginación. Todos elementos desjerarquizados por las culturas oficiales. Es desde las valoraciones hegemónicas de un arte decente, intelectualizado y "bello" que el circo fue ubicado históricamente en una escala valorativa de inferioridad, arte menor o mera curiosidad.

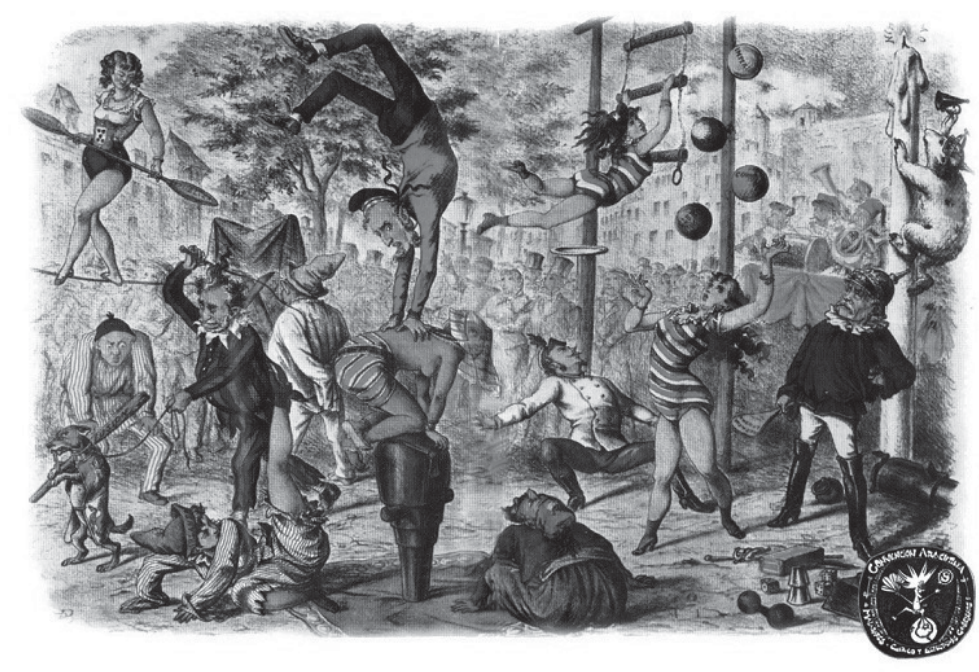

Foto 1: Ilustración de la Revista de la 5ta Convención Argentina de Malabares, Circo y Espectáculos Callejeros, 2000

En los años 80 post-dictatoriales, jóvenes artistas en su mayoría provenientes del teatro, comenzaron a recuperar los lenguajes del circo para llevarlos a plazas y parques en el espacio urbano. En este contexto, empezaron a aparecer algunos ámbitos de enseñanza en manos de artistas de tradición familiar circense, situación que amplió los canales de reproducción de estas artes históricamente transmitidas 
de generación en generación al interior de "las familias de circo". El resurgimiento de estas artes se afianza en los años 90, período en el cual se van definiendo los dos "estilos" o nuevas maneras de hacer circo entre los que se debatirá la formación cultural contemporánea: el Nuevo Circo y el Circo Callejero. Estas dos categorías nativas se encuentran en relación tensa con una tercera que es la categoría de Circo Tradicional. Sinteticemos brevemente qué se entiende al interior de la formación cultural por cada una de ellas:

Circo Tradicional: el formato de números de destrezas físicas como la acrobacia, los malabares, el trapecio, el equilibrio, introducidos por un presentador, intercalados con el humor de los payasos y el riesgo de la doma de animales, es la base de lo que actúalmente suele denominarse circo tradicional. A este modelo de espectáculo se lo conjuga con un modo particular de producción familiar en íntima relación con el carácter trashumante de la actividad circense.

Nuevo Circo: estilo genérico o variante histórica surgida a nivel internacional a partir de los 80, cuyo principal exponente es el Cirque du Soleil de Canadá. El Nuevo Circo abandona por completo ciertos elementos característicos de la tradición circense (los números de animales, el presentador). Apuesta a la fusión con otras artes y a una puesta en escena que en general incorpora un argumento a lo largo de todo el espectáculo y personajes que se repiten, utilizando casi exclusivamente el lenguaje corporal, con una fuerte apuesta a la eficacia en el uso del cuerpo y en el correcto manejo de la técnica de las distintas disciplinas circenses.

Circo Callejero: modalidad estrechamente vinculada con la utilización de técnicas circenses llevadas al espacio de actuación callejera. Es un estilo de espectáculo con una fuerte marca local que se define y afianza en Buenos Aires en los años 90.

Estas diferentes maneras de referirse a los estilos o variantes genéricas son un terreno de disputa al interior del campo. Aún cuando, como citamos en el acápite, la clasificación bajo categorías estrictas 
-como Circo Tradicional, Nuevo Circo, Circo Callejero- genere ciertas reticencias, lo cierto es que son categorías que estructuran el campo artístico, son resistidas y también utilizadas por los artistas para identificarse y diferenciarse.

Aclaremos aquí que, si bien el concepto de "estilo" conlleva una amplia carga de significados y usos cotidianos que lo tornan complejo, en este artículo lo utilizamos en primer lugar en tanto categoría nativa. Principalmente estamos interesados en analizar los usos y disputas que se establecen alrededor de los distintos modos de hacer circo. Por lo tanto, no buscamos delimitar características fijas asociadas a cada una de las categorías estilísticas sino problematizar sus usos. Los artistas recuperan y moldean el pasado, se apropian de otros géneros convencionalizados, ampliando o minimizando las "brechas intertextuales" (BAUMAN-BRIGGS, 1996). Muchas veces lo que se disputa al alejarse o acercarse de los precedentes genéricos o al incorporar intertextualidades genéricas, es la posibilidad de innovación y los límites para la misma. La pregunta que suele atravesar estas cuestiones es: ¿hasta cuándo sigue siendo Circo?

Mencionamos que para principios de los años 90 nos encontramos con la definición de los dos estilos circenses que irán disputando la resignificación del género. Analicemos ahora qué modificaciones e innovaciones fueron aportando cada una de estas variantes genéricas.

El estilo de Circo Callejero se irá definiendo en relación con una estructuración común de los espectáculos que dependerá ampliamente del contexto callejero de reproducción de los mismos. Los espectáculos callejeros circenses, aunque cada uno es único y está relacionado con la creatividad de cada artista, en su mayoría, mantienen una estructura similar dividida en los siguientes momentos: la convocatoria, como momento en el que el artista o grupo va desarrollando diversas estrategias para llamar la atención del público; el desarrollo del espectáculo; la "pasada de gorra", como momento en el que se invita a los espectadores a pagar por el espectáculo y el cierre ${ }^{5}$. Asimismo, el estilo callejero involucrará el uso de la comicidad y la comunicación con el público de manera constante: "si a la gente no la hacés participar del espectáculo, se va", suelen comentar los artistas. 


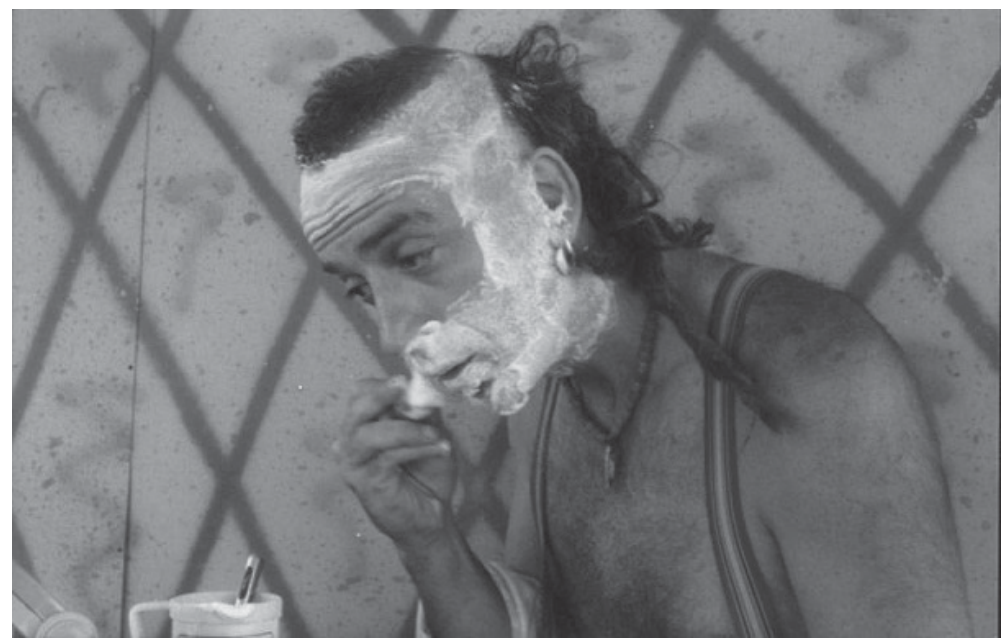

Foto 2: Payaso Chacovachi, precursor del estilo de Circo Callejero porteño

Estas performances se constituyen estilística, temática y estructuralmente en relación con el contexto callejero. Por lo cual existe una recuperación de tradiciones performativas que se remontan a los juglares, a los cómicos ambulantes, a los artistas de feria, a los carnavales. Principalmente, la utilización de este tipo de artes consideradas "populares" en un sentido bajtiniano del término ${ }^{6}$, en un espacio circular de plaza remite a dichas tradiciones. Los artistas suelen evaluar el espacio público como un ámbito que posibilita una mayor participación del público, diferente a la que se le brinda en el teatro convencional. Allí se recrea un ámbito en el que "todo vale" -por lo menos en principio- momentos en los que la gente se permite jugar, gritar, aplaudir en exceso, asombrarse, en definitiva, participar.

De este modo, el contexto de actuación callejero es lo que suele evaluarse desde los artistas como algo identificatorio, tanto del estilo artístico de las performances, como del modo de pensar el arte. En este sentido, se actualizan nociones específicas de "lo popular" para identificar la práctica artística callejera. El estilo de Circo Callejero involucrará una noción de arte vinculada a la trasgresión, liberación y oposición al arte consagrado, así como una manera "comprometida" de pensar el rol del arte y el artista en la sociedad a través de la "democratización" del acceso a las artes. La formación cultural circense se afianzó relacionando este tipo de discurso en el plano artístico con 
la posibilidad de que el arte se convierta en el proyecto laboral y en la forma de vida de los jóvenes que se acercaban a estos lenguajes artísticos. Recordemos que los neoliberales años 90 se caracterizaron por la creciente pauperización y precarización de las ofertas laborales a las que podían acceder las juventudes. En este contexto, el trabajo artístico se presentó como estrategia "alternativa" para garantizar la supervivencia -en tanto obtención de ingresos monetarios- a través del arte, así como una forma de "resistencia" cultural a partir de la que se disputaron valores y modos alternativos de trabajo y de vida.

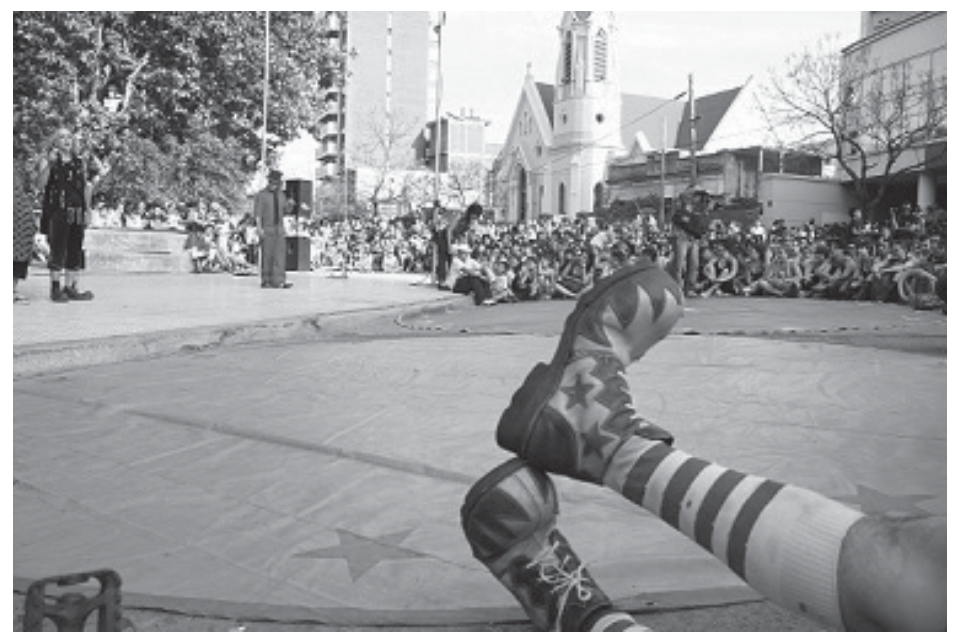

Foto 3: Espectáculo de Circo Callejero en $14^{\circ}$ Convención Argentina de Circo, Payasos y Espectáculos Callejeros, 2010

En este sentido, se afianzó una identificación del "nosotros" en vínculo con la resignificación del género artístico y de la práctica profesional. Es aquí donde comienzan a establecerse fronteras simbólicas para distinguir la propia práctica como "comprometida", "democratizadora" y "popular" -recuperando esa historia de artistas de Feria, de elementos cómicos populares conjugados en el Circo Tradicional como un arte menospreciado por los cánones hegemónicos- de otras formas artísticas evaluadas como "elitistas", "consagradas", "legitimadas".

El estilo Nuevo Circo, involucró diversas modificaciones en las apuestas artísticas que implicaron mayoritariamente un alejamiento de la estética grotesca a partir del "refinamiento" de las puestas en escena. En la búsqueda por resignificar y actualizar al género tradicional 
se realizaron innovaciones cuyo propósito se enmarcaba en la lucha contra la histórica desvalorización del género como "arte menor". Por lo tanto, las presentaciones vinculadas al Nuevo Circo comenzaron a prescindir de algunos componentes arquetípicos del género circense. En primer lugar, se descartó la utilización de animales en escena, que había sido una de las marcas de origen del circo. Las destrezas ecuestres junto a la doma de animales salvajes, eran uno de los recursos expresivos más característicos del género, colocando al espectador ante al riesgo que implicaba el hombre frente a la naturaleza en su intento por doblegarla. Más allá de las apreciaciones contemporáneas acerca de los derechos de los animales esgrimidos por asociaciones protectoras de los mismos, el uso de animales en el circo se comprende situando el recurso expresivo en la coyuntura histórica. La presencia de animales exóticos en el circo -único medio que acercaba estas imágenes a, por ejemplo, un ámbito urbano- y la posibilidad de domesticar lo salvaje, producían una fascinación poco imitable a través de algún otro recurso expresivo.

Por otra parte, el Nuevo Circo incorporó una nueva estructuración de la performance. El Circo Tradicional se definía por una sucesión de números cortos de destrezas circenses - malabares, acrobacia, equilibrio, aéreos, entre los que se incluyen trapecio, cuerda indiana, cuerda lisa, trapecio a vuelo, aro, entre otros-, sumados a la magia o prestidigitación y a las ya mencionadas destrezas ecuestres y doma de animales. Cada número o escena, con un principio y un fin, era introducida por un presentador o maestro de ceremonias. Asimismo, los payasos podían realizar un número completo de comicidad, o bien arbitrar de separadores entre uno y otro número de destreza, distrayendo la atención del público mientras se reacomodaban los elementos necesarios para el siguiente número.

Esta estructuración característica del Circo Tradicional resultaba eficaz al desarrollo de la performance por varios motivos. En primer lugar, el orden de los números y sus intérpretes podían ser intercambiados, renovando el espectáculo con mínimas reestructuraciones. Si pensamos en la trashumancia de esta modalidad artística, resultaba económicamente ventajoso permanecer la mayor cantidad de tiempo en el mismo destino (atenuando los costos del traslado de las carpas 
y los equipamientos), garantizando la presencia del público con la renovación del espectáculo. En segundo lugar, la figura del presentador y de los payasos resultaban útiles para descomprimir la tensión generada por los números de riesgo. Asimismo, en un espectáculo dirigido a "toda la familia", la sucesión de las escenas cortas posibilitaba la atención selectiva, situación que facilitaba la presencia de niños. La falta de continuidad en una argumentación a lo largo de toda la performance y la alternancia de situaciones y personajes permitían la distensión en los espectadores.

A diferencia del Circo Tradicional, la estructuración de la performance en los espectáculos vinculados al estilo Nuevo Circo involucra, generalmente, un desarrollo argumental. Los personajes que realizan las destrezas corporales son ubicados en función de esa argumentación, prescindiendo de la figura del presentador. Si bien continúan existiendo escenas delimitadas en tanto presentación de números diferenciales, los mismos intentan mantener interconexiones en función del argumento. Por otra parte, los códigos expresivos utilizados (STOELJE-BAUMAN, 1988) acentúan el lenguaje corporal -con una fuerte apuesta a la eficacia de la técnica de cada disciplina artística apoyada en un manejo efectivo del cuerpo- y los códigos visuales -escenografía, vestuario- mientras casi no incorporan el uso de la palabra. El desarrollo argumental, entonces, implica una fuerte apelación a lo metafórico. Asimismo, el código musical acompaña esa performance concebida como un todo e implica una continuidad en el plano musical. 


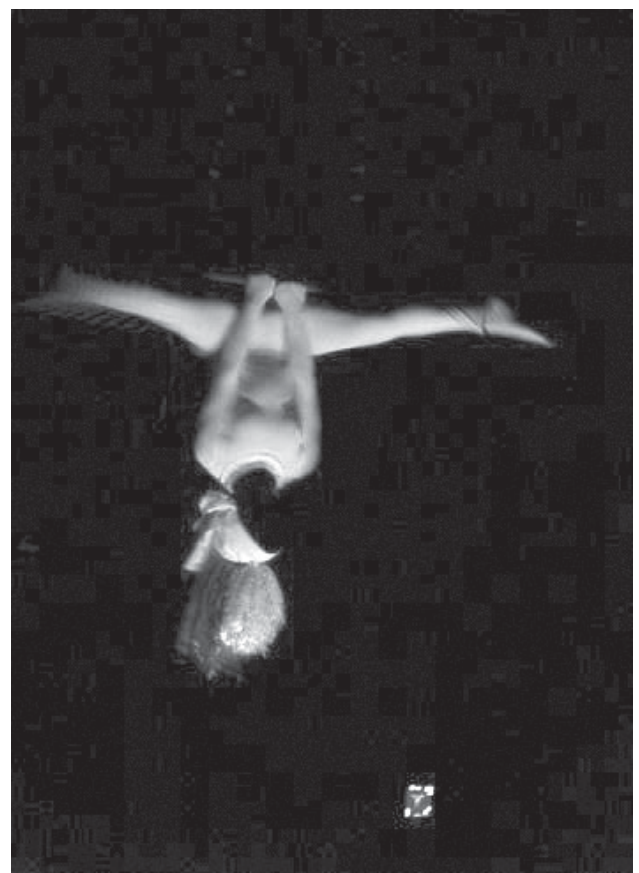

Foto 4: Trapecista utilizando recursos lumínicos (luz negra) y vestuario en espectáculo circense, 2011

La estructuración performática descripta y el cambio en los códigos y recursos expresivos utilizados es concebida como parte de la "evolución" o "refinamiento" del género, que se fue alejando de varias de sus marcas de origen: lo grotesco fue abandonándose (no suelen aparecer freaks o fenómenos, ni mujeres barbudas); se atenuó el acento en la destreza corporal per se buscando transmitir un mensaje que trascienda el foco en el riesgo y las proezas humanas; el espacio escénico se transportó a salas teatrales o a espacios escénicos con condiciones edilicias contrastantes a las de las carpas de circo, con piso de barro y aserrín; los artistas dejaron de formarse exclusivamente en el ámbito familiar, replicando los números de los abuelos o los padres, para pasar a nutrirse de una variedad de recursos de distintos géneros artísticos. 


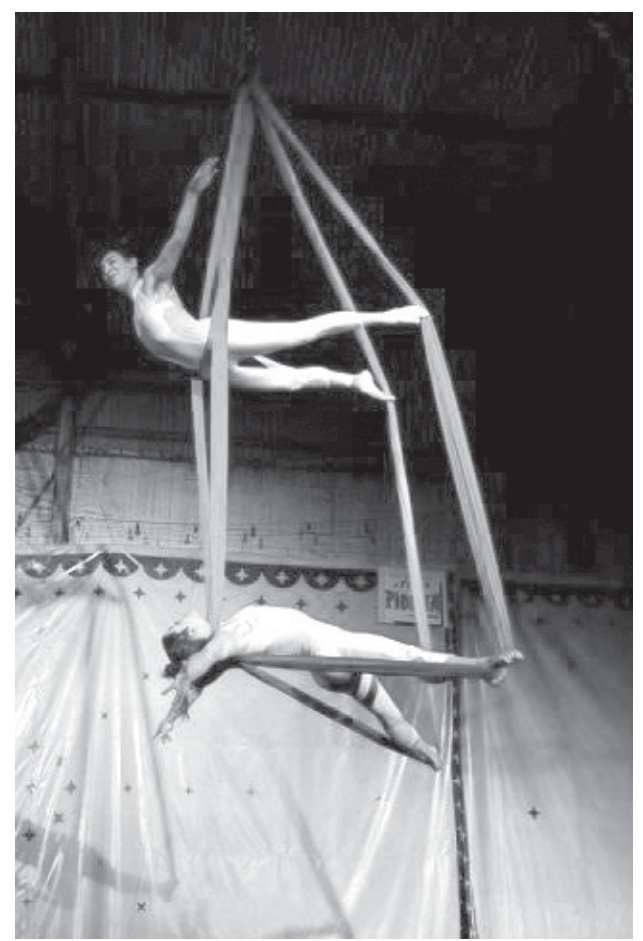

Foto 5: Artistas circenses contemporáneas en Tela, 2009.

Ahora bien, la formación cultural actual involucra apreciaciones diferentes sobre las posibilidades de renovación del género, o en términos teóricos, a la manipulación de las brechas intertextuales (BAUMAN-BRIGGS, 1996). Algunos artistas apuestan a la maximización de estas brechas, tratando de alejar sus performances del estilo tradicional, actualizando e innovando en el género. "Algunos creen que el circo es Pepino el 88 [en referencia a un histórico payaso interpretado por José Podestá a finales del s. XIX]. Yo te digo que Pepino es un hermoso personaje histórico. Igual, la materia prima es la misma, lo que cambia es el show. Hoy lo principal es transmitir emociones, más allá de mostrar proezas humanas" (Director de una obra enmarcada en el Nuevo Circo, Diario Clarín, 5/2/2009).

La estrategia de maximización de las brechas con respecto a las tradiciones genéricas implica una voluntad de alejar al género de su histórica desvalorización. El circo de "Pepino el 88" si bien "era hermoso", es representado como ese circo que fue decayendo y que 
fue históricamente desprestigiado. Por lo tanto, una estrategia válida para acceder a cierta legitimación de la propuesta performática de algunos artistas fue, justamente, maximizar la distancia entre el estilo performático actual y las tradiciones genéricas. En este sentido, el distanciamiento de algunos elementos asociados a aquel desprestigio fue una estrategia válida para pelear por un mayor reconocimiento de las artes del circo.

Frecuentemente, el debate al interior de la formación cultural en cuanto a los modos de recrear el género artístico está atravesado por la ponderación de la creatividad. Innovar, ser auténtico y genuinamente creativo, implicaría una manera de distinguir la práctica actual del pasado genérico. Los distintos sujetos, entonces, se mueven en un continuum ideal entre dos polos, una forma genérica fija y la innovación (BAUMAN-BRIGGS, 1996), recuperando y manipulando el género, dando lugar así a procesos de tradicionalización, en los que partes de ese pasado circense se tornan significantes, brindando autoridad genérica a las prácticas actuales. Justamente, el cruce con otros géneros artísticos, como la danza o el teatro propio del Nuevo Circo, involucraría una estrategia para ampliar los recursos comunicativos favoreciendo la innovación. No obstante, muchas veces no existe consenso al interior de la formación cultural para acordar cuáles son los límites para la manipulación del género. En algunos casos, alejarse tanto de la tradición genérica, puede involucrar un abandono de elementos que se consideran arquetípicos del género. En este sentido, cuando la antedicha innovación se une a la noción de "evolución" en tanto utilización de mayor complejidad de recursos comunicativos, resulta una estrategia eficaz para disputar reconocimiento y legitimación, ante ciertos parámetros valorativos hegemónicos. No obstante, un comentario frecuente entre los artistas suele ser: “¿cuánto le queda de popular, cuando se hace un espectáculo en el Konex (espacio cultural legitimado de la cuidad), para gente de clase media y promocionado por Seven Up?" (Evaluación de una artista entrevistada en 2008).

Así como algunas apuestas de Nuevo Circo pueden ser evaluadas negativamente en tanto se alejan de ciertos atributos primordiales que definirían al género, lo mismo sucede con los espectáculos de Circo 
Callejero, aunque en otro sentido. Si bien los últimos son defendidos como la continuidad de la cualidad popular del género artístico, son criticados por su falta de creatividad e innovación. "Al final terminás viendo el mismo chiste, la misma estructura, el mismo speech de pasada de gorra. No hay nuevas propuestas y los artistas terminan haciendo lo que saben que funciona en la calle y no se arriesgan. No agudizamos en el mensaje, la bajada de línea política. Yo creo que en el Circo de calle hemos involucionado en los últimos años" (apreciación de un artista callejero, entrevista Junio 2009). El Circo Callejero en su búsqueda de renovación del género también se distanció de algunos de los elementos que caracterizaban a las actuaciones del Circo Tradicional, definiéndose en un "Circo sin carpa". Este distanciamiento sirvió para buscar legitimación de la práctica en su búsqueda por democratizar el acceso a las artes -retomando aspectos arquetípicos del género que se remontan a sus orígenes, minimizando las brechas intertextuales con esa tradición original-. Pero una vez definido y consolidado el estilo, según sus propios protagonistas, no se profundizó en la creatividad ni en la innovación, replicando una fórmula efectiva y casi estandarizada.

Lo argumentado hasta aquí permite visualizar cómo la disputa al interior de la formación cultural no reside mayoritariamente en las posibilidades de manipulación estilística del género -dada la ponderación de la idea de creatividad vinculada a la innovación- sino en los aspectos concomitantes a la producción artística. En otras palabras, se disputa el mensaje que se transmite a través del arte, el contexto de reproducción del mismo y su finalidad -social, democratizante, crítica, auténtica, creativa o legitimada, efectiva y/o comercializada. Proponemos analizar en el siguiente apartado cómo se debate lo que podríamos englobar bajo la noción de rol social del arte y sus modificaciones en contextos de cambio.

\section{4 “Antes Éramos Transgresores": las disputas frente al proceso de legitimación}

¿Cuál es la proyección más reiterada por el público crítico sobre la creación cultural en el mundo moderno? La historia del creador auténtico que se vendió al consumo 
o que todavía se resiste a él. [...] Se espera siempre del artista una postura innovadora y crítica y ésta está siempre amenazada de neutralizarse por el sistema de reproducción de los valores dominantes: desechables, inmediatos, narcotizantes, netamente comerciales (CARVALHO, 1994, p. 20).

Sinteticemos algunas de las características del período de legitimación de las artes circenses desarrollado en los años 2000. Durante los 90, la renovación del Circo Tradicional se desarrolló a partir de una importante preponderancia del Circo Callejero. Si bien los espectáculos de Nuevo Circo comenzaron a realizarse en el país para principios de la década, los mismos eran escasos y desarrollados por pocos grupos que accedían a algunos espacios legitimados de arte en la ciudad. Para finales de los 90, se afianzan nuevos ámbitos de inserción artístico-laboral que involucran las contrataciones de artistas circenses en eventos de los más variados, desde promociones de productos, hasta participaciones en mega-eventos o en animaciones de fiestas (no sólo infantiles, sino también para público adulto). Los eventos se transforman en una alternativa de trabajo diferencial a la participación en compañías de Nuevo Circo -que generalmente son numerosas troupes que actúan en salas teatrales- o a la actuación en el espacio callejero.

Después del año 2001, se generan dos procesos simultáneos principalmente a causa de la crisis económica y la falta de políticas públicas de fomento de las artes circenses. Por un lado, la intensificación de la migración internacional de muchos de los representantes más profesionalizados del estilo de Circo Callejero (sobre todo estacional hacia Europa); por otro, en el ámbito local, la apertura constante y creciente de escuelas y espacios culturales privados y autogestivos.

En cuanto a "los que se fueron", retomando una frase casi acusatoria que circulaba al interior de la formación cultural, podemos describir sintéticamente cómo funcionó esta estrategia artístico-laboral en tiempos de crisis. En el primer lustro de la década, se da una importante retracción de los espectáculos de calle como consecuencia del deterioro económico del país. Si bien los "viajes a Europa" habían comenzado en la segunda mitad de los años 90, cuando los grupos artísticos locales callejeros empezaron a realizar temporadas de trabajo 
durante los meses invernales en Argentina; es a partir de 2001 cuando esta opción se intensifica. La devaluación de la moneda argentina y la diferencia paritaria entre el peso argentino y el euro provocaron el aumento de la rentabilidad de estas estrategias laborales. Por consiguiente, gran cantidad de artistas explotaron esta alternativa de trabajo, instalando nuevos circuitos de circulación de artistas locales en el ámbito internacional e intentando garantizar la fuente de ingresos a través de la práctica artístico-laboral.

Cabe destacar que, si bien los espacios de inserción artístico-laboral se habían ampliado a fines de los años 90 a través de los mencionados "eventos", en la coyuntura de crisis de principios de los años 2000, nos encontraremos con una importante retracción de la demanda y la consecuente reducción de alternativas de trabajo artístico. Además de la conveniencia económica, desde el campo artístico también se argumenta como motivo central de esta migración estacionaria la falta de estímulos locales en un contexto de crisis. En el mismo período, al compás de la migración y la crisis, algunos artistas "eligieron" otros caminos. Se quedaron en el país, luchando por generar espacios culturales propios para las artes circenses o peleando por el reconocimiento y por el ingreso de las mismas a espacios legitimados de arte en la ciudad.

Entre "los que se quedaron", la estrategia utilizada para garantizar el desarrollo de la práctica artístico-laboral fue la apertura de nuevas escuelas y espacios de enseñanza de las disciplinas circenses, en muchos casos emparentados con el estilo de Nuevo Circo. Algunos de estos ámbitos respondieron al crecimiento de la demanda de aprendizaje de estas artes e implicaron el ingreso de nuevos actores al campo. "Los talleres de circo" para niños, adolescentes y adultos fueron una oferta que apuntó a suplir una demanda que no involucraba la profesionalización en las disciplinas circenses, que había sido la característica preponderante entre los sujetos que se acercaban al circo en períodos anteriores.

Por otra parte, en otra línea de espacios culturales surgidos en esta coyuntura, se evidencia una actualización de los discursos acerca del "compromiso social" que implicaba en los 90 la práctica callejera. Se 
reeditan las nociones de independencia, autonomía y transgresión en el manejo de estos "espacios autogestivos". Los mismos son pensados como ámbitos que fomentarían modos de organización y difusión de prácticas artísticas "alternativas" a las impuestas por el mercado y por el Estado. La noción de democratización del arte que rodeaba la práctica artística callejera fue encontrando en algunos de estos espacios culturales una actualización mantenida por la realización de las actividades "a la gorra". Asimismo, la idea de "compromiso social" se actualizaba a través de nuevas modalidades de intervención artísticas: realizar espectáculos o talleres en zonas precarizadas, en cárceles, en fábricas recuperadas, en espacios ocupados, etc.

No obstante, más allá de esta ampliación en los circuitos de circulación de las artes circenses -que se incrementará en la segunda mitad de los 2000- el efecto más notorio de estos nuevos espacios de enseñanza en los primeros años de la década fue la apertura de alternativas artístico-laborales. El circuito de circulación de las artes circenses continuaba siendo bastante marginal, off o under. Será recién, en el segundo lustro de la década de los 2000, que comenzará a afianzarse el proceso de legitimación.

La mayoría de los artistas coinciden en señalar al 2004 como el año del "boom del circo". En sus narrativas, se relaciona el crecimiento y diversificación de la oferta y de la demanda de las artes circenses a la emisión de una tira televisiva en donde la protagonista, Natalia Oreiro- una actriz reconocida en la escena local- realizaba destrezas aéreas en trapecio y tela. Desde allí, "las escuelas se llenaron de chicas que querían ser trapecistas como la Oreiro" (Oscar Videla, entrevista 9/12/2008).

Más allá de la explicación causal de los relatos, lo cierto es que el efecto mediático de la telenovela mencionada tuvo su anclaje en una coyuntura que venía registrando cambios en la valoración de las artes circenses. Y por otra parte, amplificó ese crecimiento abriendo los espacios de circulación de esas artes. Como mencionamos, hasta este período, más allá del ámbito callejero y algunas pocas compañías de Nuevo Circo, el arte circense solía estar restringido a espacios under y bastante exclusivos para los miembros de la formación cultural. Lo que 
las narrativas de los artistas resaltan acerca de los efectos mediáticos de la telenovela es justamente la "masificación" que habría provocado en saberes y prácticas que, hasta el momento, eran consumidos y demandados al interior de la formación cultural.

Aún cuando dicha formación se presentaba heterogénea, se evidencia en las narrativas que reelaboran el impacto de la telenovela, la conformación de un "nosotros" con algunas características comunes, que provoca que los que se acercaron como parte de la repercusión de la tira televisiva, sean colocados como agentes externos a la formación cultural. Las características comunes que se visualizaban como marcas identitarias de la misma mayoritariamente se vinculaban a la profesionalización de los artistas. En líneas generales, la formación cultural hasta esta coyuntura no involucraba un porcentaje importante de artistas que se acercaran al aprendizaje de las técnicas circenses exclusivamente a modo de hobby -como actividad realizada en el tiempo libre extra-laboral. De esta manera, la formación cultural del momento evaluaba el acercamiento de personas de sectores sociales medios o medios altos como una consecuencia del "boom mediático", y por ende, carente de autenticidad. No obstante, esta moda generó una inyección de demanda y un aumento de posibilidades laborales en torno a la consolidación de la enseñanza a nuevos sectores sociales interesados en el género.

Mencionamos una tira televisiva pero luego prosiguieron diversos sucesos que merecen ser destacados por el modo en que fueron interactuando con la legitimación del arte circense local. En primer lugar, durante 2006 se realiza la primera visita al país del Cirque du $\underline{\text { Soleil, }}$ con el espectáculo Saltimbanco. La llegada de una megaempresa, como lo es el Soleil, con una calidad artística tan destacada a nivel mundial, provocó un gran impacto en el ámbito local. A partir de aquí, se afianza la tendencia a la ampliación de las audiencias interesadas en el género artístico circense.

Sólo parece explicable, pensando en el impacto provocado por la primera visita del Soleil, que al año siguiente (2007), se realizara un reality show titulado "El Circo de las Estrellas" por televisión abierta. Aquí se entrenaban en las disciplinas circenses actores y conductores 
de televisión, deportistas famosos, cantantes, etc., en uno de los programas de más audiencia de la televisión local, protagonizado por una conductora muy popular en el país (Susana Giménez). Los entrenadores que enseñaban las disciplinas circenses a los competidores del reality fueron personajes reconocidos en el campo artístico local. Su participación en el medio masivo fue evaluada de formas diferenciales desde la formación cultural: desde apreciaciones negativas por su vínculo con lo comercial o "mercantilizado", hasta reconocimientos de las posibilidades de divulgación y popularización de las prácticas artísticas circenses.

El caso mencionado amerita una profundidad mayor en el análisis que no es el foco de este trabajo. No obstante, cabe resaltar aquí que lo que comienza a registrarse en el campo a partir del caso, es una apelación diferencial a la noción de "popular" que implícitamente caracterizaría al arte circense. La tensión se presenta entre una connotación del término vinculada a tradiciones que equiparan lo popular a lo alternativo, impugnador y contestatario (representado, principalmente, en el estilo de Circo Callejero), frente a la "popularización" de la cultura, en tanto masificación de la oferta cultural en los medios masivos de comunicación. Si bien en ambas posturas existe una apuesta a la democratización del acceso al arte, algunos sostienen que el ingreso de las prácticas populares circenses a una programación de un medio masivo del tipo descripto, implicaría una suerte de abandono de elementos intrínsecos de la noción de "popular" sostenida, que, por ejemplo, serían la crítica y la transgresión.

La característica de los últimos años de este período es la ampliación de los circuitos y de las audiencias interesadas en estas artes. A lo ya expuesto se suma, en el segundo lustro de la década, un acceso para las artes circenses más facilitado a espacios legitimados de arte en la ciudad. Asimismo, surgirán o se afianzarán infinidad de espacios dedicados a la enseñanza y a la presentación de espectáculos circenses. Además, el crecimiento de la actividad circense se verá reflejado en distintas provincias del país, donde se realizan cada vez más Encuentros, Convenciones o Festivales de Circo. Cabe destacar que este proceso de legitimación desembocó en algunos hechos puntuales 
como el desarrollo de una política oficial de fomento de las artes del circo en la ciudad de Buenos Aires en 2009 o la apertura de carreras universitarias de artes circenses. El análisis de estas instancias que amplifican la legitimación de estas artes excede ampliamente el foco de este trabajo ${ }^{7}$.

Habíamos comenzado este apartado con una cita de Carvalho (1994) en referencia a la necesidad de hacer visible cierta "estructura de pensamiento" que distingue entre el artista que "se vende" frente al que "resiste". Más allá de visibilizarla, lo que para este estudio resulta central es problematizar el modo en que esta distinción, en el plano de las representaciones, se plantea como arena para disputar la definición de la práctica artística legítima, o en otras palabras, para construir las marcas del "nosotros" identitario. Es entonces en un contexto de cambios en los modos de producción y reproducción de la práctica artística circense, en el que se reactivan las distinciones antedichas.

En el caso trabajado, algunos de los parámetros que estructuran la disputa, además de los ya analizados, son los relacionados con la noción de rol social del arte. Es en este sentido en el que se evalúan los mensajes artísticos transmitidos -más o menos transgresores, innovadores, críticos-; los públicos a los que se orientan las actuaciones y los contextos de las mismas -en la calle para "todo el mundo" o en una sala o espacio teatral legitimado, para un público habituado a consumir arte- o en los medios masivos de comunicación. Más allá de los matices, relacionados con la diversidad de estilos que ubican a los artistas cerca o lejos de una u otra línea de conceptualización artística, la disputa atraviesa a la formación.

Una artista compartió una interesante reflexión al respecto, retomando las distinciones entre los distintos estilos genéricos que se disputan al interior de la formación cultural:

¿cómo hablar de cuál es la diferencia? Porque de alguna manera venimos todos del mismo lugar, porque no somos gente de circo, ninguno, ni los callejeros, ni los de nuevo circo. Hay mucha cosa en común, pero hay como caminos elegidos. También creo que los caminos elegidos tienen que ver con las posibilidades. La calle, la posibilidad la tiene cualquiera[... ] a la sala no accede cualquiera. [...] [En referencia a los espectáculos de 
Nuevo Circo] las temáticas que recorren para mí son lavadas, los espectáculos son lindos, lindos visualmente, en un teatro, pero lo que cuentan... quizás en la calle no siempre contás algo comprometido. Hay gente que baja mucha línea en sus espectáculos y otra que no tanto pero para mí ya estar trabajando en la calle es bajar línea aunque no estés diciendo nada. La elección de pasar la gorra y de trabajar en la calle ya es una línea ideológica, es popular, es una forma de pensar el arte (Entrevista a artista circense, abril de 2008).

El fragmento citado incorpora un análisis evaluativo del campo artístico que establece una primera distinción entre un "nosotros", en el que se incluyen a "los de nuevo circo" y "los callejeros", que se distinguen principalmente de un "otro", ese artista que es "gente de circo". La diferencia aquí tiene que ver con el reconocimiento de procedencias y trayectorias sociales distintas. Ahora bien, la artista establece nuevamente una diferenciación entre "los callejeros" y "los de nuevo circo" que se distinguen por el hecho de realizar actuaciones en contextos disímiles: la calle o la sala. De este modo, "la calle" es presentada como una elección ideológica que vincula el arte a lo popular, prescindiendo del requisito de que lo crítico y lo transgresor sea necesariamente la "bajada de línea" de un mensaje. El hecho mismo de ocupar el espacio público se presenta como "el mensaje". Otro artista callejero, Pasta Dioguardi, lo planteaba en estas palabras:

En un momento empezaron [refiriéndose a actores de teatro] a criticarnos porque decían que no había mensaje $[. .$.$] como si un hecho artístico tendría que tener$ necesariamente un mensaje político-ideológico implícito. El hecho de que cada uno [...] se pare en una plaza con su espectáculo, ya eso es un mensaje [...] Si una persona fue a una plaza con su hijo, con o sin dinero, y durante media hora se emocionó y se rió, para mí el mensaje ya esta. (Pasta en $13^{\circ}$ Convención Argentina de Circo, Payasos y Espectáculos Callejeros, 2009).

Titulamos este apartado aludiendo a una frase "nostálgica" de lectura sobre el tiempo pasado, "antes éramos transgresores", que, al mismo tiempo denota la legitimación de la formación cultural. En los últimos años se ha registrado en diversas narrativas una mirada que 
construye un "nosotros" generacional", utilizando como diacrítico el rescate de ciertas experiencias sociales significativas de los 90 -precarización, hostilidad, falta de reconocimiento a la actividad artística circense, escasez de información-. Cito algunos ejemplos:

Somos parte de una generación de artistas de circo que no nos quedamos con los brazos cruzados. Somos parte de una generación de artistas que creció sabiendo las formas y los devenires en la dura decisión de querer expresar algo artísticamente en Sudamérica (apreciación de artista callejero, 2009).

Desde que tuvimos que aprender a hacer malabares para tejer una estrategia de supervivencia para escapar de la desocupación y la miseria que nos ofrecía el menemismo ${ }^{9}$ que la tenemos clara. [...] Usamos el circo para divertir y sobrevivir, pero también lo usamos para protestar y luchar, en una combinación única que solo se da en nuestras tierras. (Fragmento de Volante en Repudio a Proyecto estatal de fomento de las artes circenses, 2009).

Cuando se evalúa que hacer circo ha sido una alternativa o "salida" laboral para "sobrevivir" y "luchar", y una forma de comprometerse "sin quedarse de brazos cruzados" a partir de llevar el arte a los espacios donde normalmente no llegaba, se está presentando una postura no solo artística e ideológica, sino también generacional. Se está retomando esa experiencia pasada para legitimar la construcción identitaria y para distinguir a un "nosotros" de los "otros", que comenzaron la práctica artística en su período de legitimación. Para ciertos artistas hacer circo en los 90 era transgresor, era popular, era un trabajo "elegido" como opción laboral y como compromiso ideológico, era inventar el modo de aprendizaje porque había muy poca información. Actualmente, existe una gran oferta de espacios de enseñanza y un mayor acceso a la información que es evaluado por los artistas que empezaron a hacer circo cuando "no había nada", cuando el aprendizaje era "intuitivo y exploratorio", cuando "todo estaba por inventarse", como una diferencia con los "recién llegados", parafraseando a Bourdieu (1990). Un artista lo plantea sobre la base de la complejidad del acceso a la información en los 90, recordando un video de Circo internacional en VHS del cuál circulaban copias: 
Y hoy por hoy... uno se mete en Internet y tenés centenas de payasos si querés. Pero en ese entonces no había nada. Entonces ver ese video era genial. [...] Todo eso era muy distinto. Somos predigitales en ese sentido. (Payaso Tomate, entrevista 4/6/2009).

Asimismo, en la actualidad hacer circo es evaluado desde estos artistas como una elección que tiene mayor aceptación social que en períodos anteriores. La mayor legitimación del arte circense provoca un cambio en la representación de la actividad, y en ese sentido, por ocupar un lugar "menos marginal", "hacer circo" ya no es evaluado como "tan transgresor". La construcción actual del "nosotros" generacional conlleva la apreciación de una cadena de significantes asociados al concepto de "transgresión": antes se transgredía desde el mensaje artístico -recuperando un arte denostado desde los cánones hegemónicos- así como disputando "alternativas" (independientes y autónomas) artístico-laborales e inaugurando nuevos espacios de actuación y nuevos proyectos de formación profesional.

El proceso de reconocimiento y legitimación va colocando a los artistas actuales ante ciertos dilemas que nos vuelven a ubicar frente a la "estructura de pensamiento" de la que hablábamos antes: ¿se "resiste" o se "transa" con las industrias culturales, el mercado o el Estado, ahora interesados en las artes circenses?, ¿se negocian los espacios de autonomía?, ¿se puede continuar transgrediendo al ocupar espacios legitimados?

Insertos en este contexto, los artistas suelen evaluar diferencialmente los ámbitos de inserción artístico-laboral. En este sentido, no se considera equiparable el trabajo callejero a ser contratado para un evento o una promoción o a trabajar en una sala teatral; se evalúa diferencialmente formar una compañía independiente o ser contratado para ser parte de un elenco en un Circo o en un Teatro. Asimismo, la participación en las ofertas laborales brindadas por las industrias culturales -publicidad o cine en donde los artistas son contratados para interpretar una escena y/o personaje- se piensa de modo diferencial a trabajar en medios masivos como la televisión. La opción docente es representada diferencialmente de acuerdo al espacio y público al que se oriente. Por ultimo, cómo gestionar un espacio cultural propio, se 
pone en debate, ya sea organizándose formalmente en una asociación civil o en una fundación para acceder a subsidios, o manteniendo autonomía de agencias estatales, buscando fuentes alternativas de financiación (INFANTINO, 2011b).

Lo que Carvalho denomina "estructura de pensamiento" que no deja de ser más que "una nueva versión del mito bíblico de la caída: lo que era puro, original (y, por lo tanto, crítico y rebelde) [...] se vende, se entrega, debido a la ambición desmesurada del artista y a la seducción implacable del mercado" (CARVALHO, 1994, p. 20), se evidencia en las representaciones diferenciales de los ámbitos de inserción artístico-laboral: en algunos se "transa" y en otros se lucha por preservar ciertos parámetros relativos a la autenticidad artística, política, ideológica que caracterizaría a la formación cultural.

\section{Reflexiones Finales}

En este trabajo analizamos cómo los protagonistas del resurgimiento de las artes circenses en la Buenos Aires postdictatorial se acercaron o alejaron de la tradición genérica, manipulando y resignificando el género en tiempos de cambio. Resulta interesante destacar que la "renovación" del estilo circense local estuvo ampliamente vinculada a la disputa por lograr el reconocimiento de las artes circenses y revertir el histórico desprestigio de las mismas, intentando instalar a estos lenguajes como otra teatralidad legítima y no como un arte "menor" y desvalorizado. En este sentido, el distanciamiento de algunos elementos asociados a aquel desprestigio -como distintos elementos propios del estilo tradicional desarrollado en las humildes carpas de lona, con pisos embarrados mezclados con aserrín- fue una estrategia válida para pelear por un mayor reconocimiento social de las artes circenses. De hecho, tanto los artistas identificados con el estilo de Circo Callejero o con el de Nuevo Circo fueron encontrando su anclaje identitario en la realización de un "Circo sin carpa", ya sea orientado al espacio callejero o a las salas teatrales.

Lo interesante de la coyuntura actual es justamente el debate en cuanto a lo que se gana y se pierde en la renovación del género. Una vez lograda una mayor legitimación de estas artes en la ciudad marcada 
por el acceso, aunque aún no generalizado, de este género artístico a espacios valorizados o hasta a proyectos de fomento estatal, la formación artística deja entrever las contradicciones frente a algunos de los elementos de los que las performances actuales se estarían alejando, centralmente, los vinculados con un género artístico históricamente considerado "popular". En este sentido, analizamos el modo en que los artistas debaten el rol social del arte que desarrollan, activando diversos diacríticos entre los que se destaca una construcción generacional que selecciona ciertos aspectos en vínculo con la experiencia de la recuperación de estas artes durante los años '90. Estudiamos cómo en la construcción del "nosotros" identitario se pondera el vínculo que las performances callejeras tendrían en tanto se acercan a ciertos precedentes genéricos vinculados con una noción particular de transgresión y crítica, que se estaría perdiendo en tiempos de legitimación.

De hecho, algo de esto es lo que está llevando a los artistas a unirse para pensar en otro tipo de estrategias, para garantizar que la renovación del género no esté exclusivamente marcada por los designios del mercado. En este contexto, los artistas están generando instancias colectivas de organización para demandar al Estado la formulación de proyectos y reglamentaciones, que fomenten intervenciones estatales para garantizar la continuidad y mejora de las prácticas circenses en el país ${ }^{10}$. En sus discursos se argumenta la importancia de contar con líneas de subvención específicas para los artistas circenses locales, que les permitan explorar diversas alternativas de reformulación del género y no sólo las que funcionan demandadas por el mercado. En palabras de un artista entrevistado:

Es importante que contemos con oportunidades para que podamos indagar en nuevas cosas, sin copiar al Soleil, inventando o retomando algunas de nuestras marcas locales del circo $[\ldots]$ Pero es muy difícil, tanto en salas como en el espacio callejero, porque si no tenés una forma de financiar la experimentación terminás siempre haciendo lo mismo, lo que funciona, lo que vende (artista callejero, 2011).

Consideramos que la antedicha organización de los artistas garantizará o deberá luchar, para que el crecimiento y la legitimación de las 
artes circenses respondan a los intereses colectivos de sus protagonistas y no se encuentre librada exclusivamente a la demanda del mercado.

\section{Notas:}

1 Agradecimientos: Presento en este artículo una síntesis de algunos de los ejes de mi Tesis Doctoral denominada "Cultura, Jóvenes y Políticas en disputa. Prácticas circenses en la ciudad de Buenos Aires". Agradezco inmensamente el aporte de cada uno de los protagonistas de la historia del resurgimiento del arte circense en la ciudad de Buenos Aires, esos artistas que experimentaron, innovaron, disputaron y recrearon las artes del circo. Sin ellos esta historia no hubiera existido ni podría ser contada. Este trabajo ha sido financiado por una beca doctoral del Consejo Nacional de Investigaciones Científicas y Técnicas (CONICET).

2 Sección de Antropología Social (SEANSO), Instituto de Ciencias Antropológicas, Universidad de Buenos Aires/ Investigadora Asistente Consejo Nacional de Investigaciones Científicas y Técnicas (CONICET). Facultad de Filosofía y Letras-UBA: Puán $480,4^{\circ}$ piso, of. 403 bis

3 El foco de nuestro trabajo de investigación doctoral estuvo centralizado en la ciudad de Buenos Aires, lo sucedido en otras regiones de la Argentina excede esta investigación. Para la misma se ha trabajado desde 2007 (aunque el caso de los artistas circenses en Buenos Aires viene siendo referente empírico desde investigaciones anteriores comenzadas en 1999). A partir de distintas técnicas habituales en antropología social basadas sobre el trabajo de campo, la observación participante y entrevistas abiertas, semiestructuradas y estructuradas, individuales y/o grupales, y en profundidad a artistas referentes del campo, a responsables de la gestión de políticas públicas, a directores de espacios de enseñanza, docentes, estudiantes iniciales y avanzados, entre otros.

4 El concepto de formación cultural propuesto por Raymond Williams lleva a problematizar cómo, en distintos contextos, los artistas se unen para la prosecución común de objetivos específicamente artísticos. El autor destaca las dificultades metodológicas para el estudio de las formaciones culturales ya que suelen caracterizarse por una escasa formalidad, por un número pequeño de personas, por una duración breve de la organización, por una complejidad de rupturas y fusiones internas. No obstante, el concepto de formación cultural posibilita estudiar modos organizativos, experiencias compartidas, puntos de conjunción, así como fracciones y disputas al interior de los grupos y con agentes externos a los mismos (WILLIAMS, 1981).

5 El payaso Chacovachi es reconocido en el campo por su trayectoria de actuación en el espacio público, sobre todo en Plaza Francia durante los años 90. Ha implementado y transmitido esta estructuración del espectáculo de calle en charlas y clases. De hecho, actualmente dicta cursos, en el país y en el extranjero, denominados: "Manual y guía para el payaso callejero".

6 Mijail Bajtín en "La cultura popular en la Edad Media y en el Renacimiento: el contexto de François Rabelais" (1985 [1941]) aborda a la cultura popular como inversión de "lo establecido", como cultura de subversión y oposición a "la cultura oficial". Según ese autor, durante la Edad Media existían diversos ritos y espectáculos que constituían la cultura cómica popular. La característica fundamental de estos festejos, de los cuales el carnaval se podría considerar su expresión más intensa, era la subversión del orden social, o sea, la oposición a la visión que la 
Iglesia y el Estado daban del mundo. Más allá de críticas y valoraciones que se han hecho sobre la obra de Bajtín, el vínculo entre cultura popular y transgresión, liberación y oposición a la cultura oficial fue uno de los sentidos más extendidos en el discurso de los artistas al pensar contemporáneamente "lo popular".

7 Para un análisis sobre las implicancias y conflictos desatados ante la intervención estatal en la promoción de las artes circenses en la ciudad de Buenos Aires se puede consultar: INFANTINO, $2011 \mathrm{la}, 2012$.

8 Diversos autores que han abordado el "problema de las generaciones" plantean que la situación generacional -como también la de clase- suele circunscribir a los individuos en un campo de posibilidades determinado y favorecer así un modo específico de experiencia, de pensamiento y de intervención en el proceso histórico. (MANNHEIM 1928 [1993]). La cuestión generacional no se trataría de una cuestión meramente cronológica, que involucre a toda la sociedad en una coyuntura particular de la misma manera, sino más bien se trata de compartir experiencias sociales significativas, y "que esas experiencias sociales sean las "originarias", las primeras que una cohorte de edad experimenta colectivamente, las experiencias con las que "nace" como actor en determinado ámbito o arena social. (KROPFF, 2008, p. 18). Lo que nos interesa aquí es justamente problematizar el modo en que en las narrativas actuales, los artistas recuperan ciertas experiencias sociales para la construcción identitaria.

9 En referencia al período de presidencia de Carlos Saúl Menem que gobernó el país en dos mandatos consecutivos durante la década del 90, también conocida como la larga década neoliberal.

${ }^{10}$ En Argentina, las artes circenses no cuentan con organismos específicos de fomento como lo hacen otros lenguajes artísticos como la danza, la música, el teatro.

\section{Referencias}

APPADURAI, Arjun. La modernidad desbordada. Dimensiones culturales de la globalización. México: Ediciones Trilce-FCE, 1996 [2001].

BAJTÍN, Mijail. La cultura popular en la Edad Media y en el Renacimiento. El contexto de Francois Rabelais. Madrid: Alianza, 1985.

BAJTÍN, Mijail. El problema de los géneros discursivos. En: Estética de la creación verbal. México: Siglo XXI. 5. ed, 1992 [1979]. p. 248-293.

BARTH, Fredrik. Introducción. En: BARTH, Fredrik. (comp.). Los grupos étnicos y sus fronteras. La organización social de las diferencias culturales. México: Fondo de Cultura Económica, 1976.

BAUMAN, Richard. Identidades diferenciales y base social del folclore. En: Serie de Folclore. n. 7, Buenos Aires: FFyL, Universidad de Buenos Aires, 1972. p. 27-46.

BAUMAN, Richard. Folklore, Performance y Género. En: Folklore, Cultural Performances and Popular Entertainments. A Communications - centered Handbook. Oxford University Press: New York Oxford, 1992. 
BAUMAN, Richard; BRIGGS, Charles. Género, Intertextualidad y Poder Social. En: Revista de Investigaciones Folklóricas, Buenos Aires: RIF; n. 11, 1996. p. 78 - 108.

BOURDIEU, Pierre. Algunas propiedades de los campos. En: Sociología y Cultura. México: Grijalbo, 1990.

BRUBAKER, Rogers; Frederick COOPER. Más allá de identidad. En: Apuntes de Investigaciones del CECYP, Buenos Aires: Fundación del sur, Año V, N. 7, 2001. p. 30-67.

CARVALHO, José Jorge. La presencia de las tradiciones folklóricas en la industria cultural. En: Revista de Investigaciones Folklóricas, Buenos Aires: RIF, n. 9, 1994. p. 18-25.

GARCÍA CANCLINI, Néstor. Diferentes, Desiguales y Desconectados. Mapas de la Interculturalidad. Barcelona: Gedisa, 2004.

GIMÉNEZ, Gilberto. Materiales para una teoría de las identidades sociales. San Andrés Totoltepec: Instituto de Investigaciones Sociales de la UNAM, 1997.

HALL, Stuart. Introducción: ¿Quién necesita la 'identidad'? En: HALL, Stuart y DU GAY, Paul (editores) Questions of cultural identity. Londres: Sage Publications, Traducción de Natalia Fortuna, 1996.

INFANTINO, Julieta. Artes entre Políticas Culturales e intervenciones sociopolíticas en Buenos Aires. En: Revista Nómadas, Bogotá: IESCO, Universidad Central, n. 34, 201 la. p. 13-29.

INFANTINO, Julieta.Trabajar como artista. Estrategias, prácticas y representaciones del trabajo artístico entre jóvenes artistas circenses. Cuadernos de Antropología Social. Buenos Aires: FFyL - UBA, n. 34, 201 lb. p. 141-163.

INFANTINO, Julieta. Cultura, Jóvenes y Politicas en disputa. Prácticas circenses en la ciudad de Buenos Aires. Tesis Doctoral con mención en Ciencias Antropológicas - Facultad de Filosofía y Letras, Universidad de Buenos Aires, Buenos Aires, 2012.

MANNHEIM, Kart. El problema de la Generaciones. En: Revista española de Investigaciones Sociológicas, Madrid: CIS, REIS n. 62,1993 [1928]. p. 193242. Disponible en: < http://www.reis.cis.es/REIS/PDF/REIS_062_12.pdf>. Acceso: 3/8/2009.

KROPFF, Laura. Construcciones de aboriginalidad, edad y politicidad entre jóvenes mapuche. Tesis Doctoral con mención en Ciencias Antropológicas - Facultad de Filosofía y Letras, Universidad de Buenos Aires, Buenos Aires, 2008. 
REGUILLO CRUZ, Rossana. Emergencia de culturas juveniles. Estrategias del desencanto. Buenos Aires: Grupo Editorial Norma, 2000.

SEIBEL, Beatriz. Historia del Circo. Biblioteca de Cultura Popular 18. Buenos Aires: Ediciones del Sol, 1993.

STOELTJE, Beberly; BAUMAN, Richard. La semiótica de la actuación folklórica. En: SEBEOK, T.; UNIKER-SEBEOK, J. (Ed.) The Semiotic Web. Berlín, Nueva Cork, Ámsterdam: Mouton de Gruyter, 1988. p 585-599. Traducción en: Ficha de cátedra Folklore General. Buenos Aires: Oficina de Publicaciones de la Facultad de Filosofía y Letras, UBA.

WILLIAMS, Raymond. Cultura. Sociología de la comunicación y el arte. Buenos Aires: Paidós, 1981.

Recebido em 29/07/2013

Aceito em 26/09/2013 